\title{
Inhibitory effect of novel Eugenol Tosylate Congeners on pathogenicity of Candida albicans
}

\author{
Shabir Ahmad Lone ${ }^{1}$ (D) and Aijaz Ahmad ${ }^{1,2^{*}}$ (D)
}

\begin{abstract}
Background: The global prevalence of fungal diseases is increasing rapidly, which affects more than a billion people every year with significant mortality rate. On the other hand, the development of new drugs to treat these fungal infections is slow, while the current antifungal therapy is insufficient and associated with adverse side effects and emerging multidrug resistance. Therefore, development of novel antifungal drugs with least or no toxicity and multi-target mechanisms of action is an immediate priority. Natural products have long been known to possess antimicrobial activities and are source of new drugs. Currently, modifying natural products to synthesize derivatives/ analogues are of great scientific focus for discovering novel drugs with improved potency and safety. Modifications in eugenol to synthesize eugenol derivatives with enhanced antifungal activity have already been reported.

Methods: In this study, three most active novel eugenol tosylate congeners (ETC-5, ETC-6 and ETC-7) were selected from our previous study to investigate their effect on major virulence factors of Candida albicans which include adherence, morphogenesis, hydrolytic enzymes secretion, biofilm formation and on expression of genes related to these virulence factors. Adherence and biofilm formation were studied by alamarBlue dye and XTT reduction assays respectively, hydrolytic enzyme secretion was evaluated by plate assays. Further, morphological transition was monitored microscopically and RT-qPCR was used to assess the gene expression levels.

Results: ETCS significantly inhibited adherence in C. albicans with an inhibition range of 16-66\%, and completely inhibited the morphogenesis at MIC values. Inhibition of proteinase and phospholipase activity was in the range of $2-48 \%$ and $8-34 \%$ respectively. Test compounds also significantly inhibit biofilm formation in C. albicans in the range of $7-77 \%$. Furthermore, RT-qPCR results indicated a significant down regulation in expression levels of genes ( ALS1, ALS2, ALS3, ALS9, CPH1, HWP1, SAP1, SAP2, SAP3 and PLB1) in C. albicans cells after treated with ETCS.
\end{abstract}

Conclusion: The results indicated that these novel ETCs target major virulence factors of $C$. albicans and avert this commensal microbe to turn into pathogenic. However, further in-depth studies may facilitate the mechanisms involved by ETCs in targeting these virulence factors.

Keywords: Candida albicans, Eugenol tosylate congeners, Virulence factors, Biofilm

\footnotetext{
*Correspondence: Aijaz.Ahmad@nhls.ac.za; Aijaz.Ahmad@wits.ac.za

${ }^{1}$ Clinical Microbiology and Infectious Diseases, School of Pathology, Health

Sciences, University of the Witwatersrand, Johannesburg 2193, South Africa

${ }^{2}$ Infection Control, Charlotte Maxeke Johannesburg Academic Hospital,

National Health Laboratory Service, Johannesburg 2193, South Africa
}

(C) The Author(s). 2020 Open Access This article is licensed under a Creative Commons Attribution 4.0 International License, which permits use, sharing, adaptation, distribution and reproduction in any medium or format, as long as you give appropriate credit to the original author(s) and the source, provide a link to the Creative Commons licence, and indicate if changes were made. The images or other third party material in this article are included in the article's Creative Commons licence, unless indicated otherwise in a credit line to the material. If material is not included in the article's Creative Commons licence and your intended use is not permitted by statutory regulation or exceeds the permitted use, you will need to obtain permission directly from the copyright holder. To view a copy of this licence, visit http://creativecommons.org/licenses/by/4.0/ The Creative Commons Public Domain Dedication waiver (http://creativecommons.org/publicdomain/zero/1.0/) applies to the data made available in this article, unless otherwise stated in a credit line to the data. 


\section{Background}

Candidiasis, caused by different Candida species is one of the most identified causes of hospital acquired infections with approximately 700,000 deaths worldwide annually [1-3]. Candida species are the 2nd most common causative agents of fungal infections worldwide and ranked 5th among hospital-acquired pathogens $[4,5]$. However, 90\% of invasive fungal infections due to Candida species are mostly attributed to Candida albicans, Candida tropicalis, Candida glabrata, Candida krusei and Candida parapsilosis [6]. Among these C. albicans remains the main causative agent [7]. C. albicans is an opportunistic pathogen, causing disease mainly in immunocompromised individuals and is associated with high morbidity and mortality rates $[8,9]$. However, transition from the commensal to the pathogenic form involves several biochemical and morphological changes, which are known as virulence factors. The important virulence factors associated with $C$. albicans pathogenesis include adherence, morphogenesis, hydrolytic enzymes secretion and biofilm formation [10].

Adhesion to host cells is an important first step to initiate fungal infection. Following adherence, planktonic yeast form $C$. albicans cells transits to pathogenic hyphae forms leading to tissue invasion and biofilm formation [11-14]. Following hyphae formation, C. albicans cells secrete hydrolytic enzymes mainly proteinases and phospholipases, which are responsible for host tissue invasion [15]. With the increasing use of biomaterials, implants and use of medical catheters, $C$. albicans biofilm formation has drastically increased, which is directly correlated to increase in drug resistance. C. albicans biofilms are inherently resistant to most conventional antifungal drugs [16]. Moreover, currently available antifungal drugs are inadequate and constricted with limitations such as severe toxicity, narrow antifungal spectrum, emerging drug resistance and high costs [17, 18]. Thus, finding new antifungal drugs with alternative and multi-target mechanisms of action to develop more effective antifungal therapy has become an essential medical priority, especially to target multidrug resistant Candida species and resistant virulent forms such as biofilms.

Natural products are known for their antimicrobial activity; however, due to several limitations only few antifungals find their way to the clinics $[19,20]$. Currently, modifying natural products to synthesize derivatives are of great interest to researchers for discovering novel molecules with improved potency and safety. Research in this area is promising for the development of new antifungal agents. Numerous studies have already reported that derivatization of eugenol enhanced its antifungal activity [19-23]. In our previous studies, we also reported that eugenol tosylate congeners (ETCs) possess potent antifungal activity by inhibiting the ergosterol biosynthesis pathway in C. albicans [19]. Based on our previous findings, we further modified eugenol to synthesis ETC with different functional groups and tested their antifungal activity against different $C$. albicans isolates [24]. In continuation to this study, we selected the three most active ETCs listed in Table 1 (ETC-5, ETC-6 and ETC-7) to explore their effect on major virulence factors of $C$. albicans in fluconazole susceptible and resistant $C$. albicans strains. The effect of these compounds on expression of genes related to pathogenicity of C. albicans has also been investigated.

\section{Methods}

\section{Organisms and growth conditions}

C. albicans strains including fluconazole susceptible $C$. albicans 4175, fluconazole resistant C. albicans 5112 and control strain C. albicans SC5314 (ATCC MYA2876) were used in this study. The clinical isolates were collected from patients visiting Charlotte Maxeke Johannesburg Academic Hospital, and for their presumptive identification germ tube assay and the $\mathrm{API}^{\circledR} 20 \mathrm{C}$ AUX test kit (bioMérieux, France) were used. After identification all these isolates were stored in Sabouraud Dextrose broth (SDB) at $-80{ }^{\circ} \mathrm{C}$ supplemented with $20 \%$ glycerol in the Department of Clinical Microbiology and Infectious Diseases, University of the Witwatersrand, Johannesburg. The ethical clearance number M000402 obtained from the Human Research Ethics Committee, University of the Witwatersrand was used for these isolates. For experimental purposes each strain from the glycerol stock was recovered on Sabouraud Dextrose agar (SDA) plates at $37^{\circ} \mathrm{C}$ for $24 \mathrm{~h}$.

\section{Chemicals and drugs}

All culture media and other chemicals used in this study were of high analytical grade. Sabouraud dextrose broth (Cat No-S3306), Sabouraud dextrose agar (Cat No84088), RPMI-1640 Medium (Cat No-R6504), Phosphate buffered saline (Cat No-P4417), Fetal Bovine Serum (Cat No-F3885), Agar (Cat No-05040), Bovine Serum Albumin (Cat No-A9418), Yeast Nitrogen Base without Amino Acids (Cat No-Y0626), Ammonium sulphate (Cat No-A4418), Glucose (Cat No-G8270), Peptone (Cat No-77199), Sodium chloride (Cat No-S1679), Calcium chloride (Cat No-C1016), Egg Yolk Emulsion (Cat No17148), MOPS (Cat No-M1254), XTT (Cat No-X4626), Menadione (Cat No-M5625), Acetone (Cat No-650501) were purchased from Sigma - Aldrich, St. Louis, MO, USA. 
Table 1 Eugenol tosylates congeners and their structures

\begin{tabular}{lll}
\hline Compound & Ligand name & Ligand structure \\
\hline ETC-5 & 4-allyl-2-methoxyphenyl 4-(trifluoromethyl) benzene \\
ETC-6 & 4-allyl-2-methoxyphenyl 4-(trifluoromethoxy) benzene \\
4-((4-allyl-2 methoxyphenoxy) sulfonyl) benzoic acid &
\end{tabular}

${ }^{a}$ Minimum inhibitory concentrations are based on our previous findings [24]

\section{Effect on virulence factors}

The effect of three eugenol tosylate congeners at varying concentrations of ETC-5: $0.25 \times \mathrm{MIC}(0.032-0.25 \mu \mathrm{g} /$ $\mathrm{ml}), \quad 0.5 \times \mathrm{MIC}(0.063-0.5 \mu \mathrm{g} / \mathrm{ml})$ and $1 \times \mathrm{MIC}(0.125-$ $1 \mu \mathrm{g} / \mathrm{ml}), \quad$ ETC-6: $0.25 \times \mathrm{MIC}(0.063-0.5 \mu \mathrm{g} / \mathrm{ml}), 0.5 \times$ MIC $(0.125-1 \mu \mathrm{g} / \mathrm{ml})$ and $1 \times \operatorname{MIC}(0.25-2 \mu \mathrm{g} / \mathrm{ml})$ and ETC-7: $0.25 \times$ MIC $(0.25-2 \mu \mathrm{g} / \mathrm{ml}), 0.5 \times$ MIC $(0.5-4 \mu \mathrm{g} /$ $\mathrm{ml})$ and $1 \times \mathrm{MIC}(1-8 \mu \mathrm{g} / \mathrm{ml})$ on major virulence factors of $C$. albicans including adherence, morphogenesis, hydrolytic enzymes secretion, and biofilm formation have been studied, as these virulence factors can be utilised as emerging drug targets to develop new and effective antifungal drugs.

\section{Adherence assay}

The adherence assay was performed using the technique described by Fazly et al., 2013 [25]. Briefly, $100 \mu \mathrm{l}$ of $C$. albicans cells $\left(1 \times 10^{6}\right.$ cells $\left./ \mathrm{ml}\right)$ grown in RPMI 1640 medium and buffered with $0.165 \mathrm{M}$ Mops at $\mathrm{pH} 7.0$ (Sigma - Aldrich, St. Louis, MO, USA) were inoculated into each well of Immulon 2HB 96-well microtiter plate. Cells were then exposed to different concentrations $(0.25 \times \mathrm{MIC}, 0.5 \times \mathrm{MIC}$ and $1 \times \mathrm{MIC})$ of ETC-5, ETC-6 and ETC-7 and incubated at $37{ }^{\circ} \mathrm{C}$ for $3 \mathrm{~h}$. Untreated control cells were kept in every set of experiment as negative control. Subsequently incubation medium was removed and each well was washed two times with $200 \mu \mathrm{l}$ PBS to remove non-adherent cells. A $100 \mu \mathrm{l}$ of alamarBlue (Life Technologies) at a final concentration of $5 \%$ in RPMI 1640 medium were added to each well followed by incubation at $37^{\circ} \mathrm{C}$ for $2 \mathrm{~h}$. Fluorescence signals were read at $555_{\mathrm{Ex}} / 585_{\mathrm{Em}}$ using a BioTek Synergy HT microplate reader (BioTek Instruments, WA, USA).

\section{Morphogenesis}

The effect of test compounds on yeast to hyphae transition was determined using a protocol described by Yousuf et al., 2011 with modifications [26]. C. albicans cells were sub-cultured up to late log phase in SD Broth at $37^{\circ} \mathrm{C}$. Cells were then transferred into fresh SD broth followed by incubation at $37^{\circ} \mathrm{C}$ for $48 \mathrm{~h}$, for a synchronised cell population. Further, to induce hyphal formation $50 \mu \mathrm{l}$ of synchronised cell population were transferred into $10 \mathrm{ml}$ of fresh SD broth supplemented with $10 \%$ Fetal bovine serum (FBS) at pH 6.5. Varying concentrations of test compounds $(0.25 \times \mathrm{MIC}, 0.5 \times$ MIC and $1 \times$ MIC) were added to the medium, followed by incubation at $37^{\circ} \mathrm{C}$. External pH of the medium was maintained at $\mathrm{pH} 6.5$ and hyphae formation was observed microscopically using a Leica DM 500 microscope (Leica Microsystems, Heerbrugg Switzerland) by taking aliquots of $10 \mu \mathrm{l}$ after $180 \mathrm{~min}$. An untreated sample was also included as control.

\section{Proteinase assay}

A proteinase assay was performed using a plate assay method described by Yousuf et al., 2011 with modifications [26]. C. albicans cells were sub-cultured in $5 \mathrm{ml} \mathrm{SD}$ broth and incubated for $18 \mathrm{~h}$ at $37^{\circ} \mathrm{C}$. Cells were centrifuged at $3000 \mathrm{rpm}$ for $5 \mathrm{~min}$ and resuspended in fresh medium. The cells were then exposed to desired concentrations of test compounds as mentioned above for $3 \mathrm{~h}$. 
Cells without treatment served as negative control. Aliquots of $2 \mu \mathrm{l}$ were placed at equidistant points on proteinase agar plates (agar 2\%, BSA $2 \mathrm{~g}$, yeast nitrogen base without amino acids, ammonium sulphate $1.45 \mathrm{~g}$, glucose $20 \mathrm{~g}$ and distilled water $1000 \mathrm{ml}$ ). The plates were incubated for 3-4 days and then examined for proteinase activity by measuring clear zones of degradation using the formula:

$$
\mathrm{Pz}=\frac{\text { diameter of colony }}{\text { diameter of colony }+ \text { zone of degradation }}
$$

\section{Phospholipase assay}

C. albicans cells were exposed to different concentrations of test compounds for $3 \mathrm{~h}$ as described above. Aliquots of $2 \mu \mathrm{l}$ were taken and placed on phospholipase agar plates (agar 2\%; peptone $10 \mathrm{~g}$; glucose $30 \mathrm{~g} ; \mathrm{NaCl}$ $57.3 \mathrm{~g} ; \mathrm{CaCl}_{2} 0.55 \mathrm{~g}$ and distilled water $900 \mathrm{ml}$ enriched with $10 \%$ egg yolk emulsion) at equidistant points. The plates were incubated at $37^{\circ} \mathrm{C}$ for $2-4$ days and phospholipase activity was determined by measuring precipitation zones around the colonies [27]. Zones of precipitation were calculated as mentioned above.

\section{Biofilm formation}

Biofilms were formed in flat-bottom 96-well microtiter plates by inoculating $C$. albicans cell suspensions $(1 \times$ $10^{6}$ cells $/ \mathrm{ml}$ ) in RPMI 1640 medium buffered with 0.165 M Mops pH 7.0 and incubated at $37^{\circ} \mathrm{C}$ for $2 \mathrm{~h}$ [28]. After a $2 \mathrm{~h}$ adhesion period, the medium was removed carefully without disturbing the biofilm formation, and then varying concentrations of test compounds were prepared in fresh RPMI 1640 medium and added to the plate wells. The plates were further incubated at $37^{\circ} \mathrm{C}$ for $24 \mathrm{~h}$ and $48 \mathrm{~h}$. Effect of test compounds on biofilm formation were estimated using semi-quantitative XTT reduction assay.

\section{$\mathrm{XTT}$ reduction assay}

A 2,3-Bis (2-methoxy-4-nitro-5-sulfo-phenyl)-2H-tetrazolium-5-carboxanilide (XTT) reduction assay was performed following the method described by Jin et al., 2004 [29]. Briefly, XTT $(1 \mathrm{mg} / \mathrm{ml})$ in PBS and a solution of menadione $(0.4 \mathrm{mM})$ in acetone was prepared. XTT menadione solution was prepared fresh before each assay at a volume ratio of 20:1. The pre-formed biofilms were washed two times with PBS, then XTT $(40 \mu \mathrm{l})$, menadione $(2 \mu \mathrm{l})$ and PBS $(158 \mu \mathrm{l})$ were added to each well of microtiter plates. The plates were incubated in the dark at $37^{\circ} \mathrm{C}$ for $3 \mathrm{~h}$. After incubation, the solution $(100 \mu \mathrm{l})$ was transferred to each well of a new microtiter plate. The colorimetric changes were measured at 490 $\mathrm{nm}$ using iMark microplate reader (Bio-Rad laboratories,
CA, USA). Reduction of XTT is directly correlated to the metabolic activity of biofilms.

\section{Gene expression analysis}

Effect of ETCs on the expression of the genes for adherence (ALS1, ALS2, ALS3 and ALS9), morphogenesis (CPH1, HWP1), proteinases (SAP1, SAP2, and SAP3) and phospholipases (PLB1) was evaluated by RT-qPCR using method described by Ahmad et al., 2015 with modifications [19]. Briefly, C. albicans cells at a concentration of $5 \times 10^{6}$ cells $/ \mathrm{ml}$ were exposed to the MIC of test compounds followed by incubation at $37^{\circ} \mathrm{C}$ for $3 \mathrm{~h}$. Untreated cells were used as negative control. Total RNA was extracted using Quick-RNA Fungal/Bacterial Miniprep Kit (Zymo Research, CA, USA) following the manufacturer's instructions. Concentration of total RNA was measured using a Nanodrop 2000 spectrophotometer (Thermo Scientific, MA, USA). Thereafter, cDNA was synthesised using a iScript ${ }^{\text {tw }}$ cDNA synthesis kit (Bio-Rad, CA, USA) as per manufacturer's instructions. Primers for the above mentioned targets and housekeeping genes (ACT1, PMA1 and $R P P 2 B$ ) were designed using NCBI/Primer3-Blast (https://www.ncbi.nlm.nih. gov/tools/primer-blast/) (Table 2) and synthesized from Integrated DNA Technologies, IA, USA. RT-qPCR was performed using PowerUp ${ }^{\text {Tu }}$ SYBR $^{\text {ma }}$ Green Master Mix (2X) (Thermo Fisher Scientific, MA, USA) in a RocheLight ${ }^{\circ}$ Cycler Nano instrument Real-time PCR system (Roche, Basel, Switzerland). The following thermal cycling conditions for all RT-qPCR reactions were used; UDG activation at $\left(50^{\circ} \mathrm{C} / 2 \mathrm{~min}\right)$, initial denaturation $\left(95^{\circ} \mathrm{C} / 2 \mathrm{~min}\right)$, followed by 40 cycles of denaturation $\left(95^{\circ} \mathrm{C} / 15 \mathrm{~s}\right)$, annealing $\left(50^{\circ} \mathrm{C} / 60 \mathrm{~s}\right)$, and extension $\left(72{ }^{\circ} \mathrm{C} /\right.$ $60 \mathrm{~s})$. Melting curve analysis was performed to confirm the specificity of the primers. Furthermore, efficiency of the amplifications was confirmed by analysing the standard curves of both the target and housekeeping genes. Relative expression fold changes were assessed by $\Delta \Delta \mathrm{CT}$

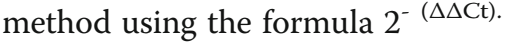

\section{Statistical analysis}

Two-way ANOVA followed by Dunnett's multiple comparisons test was used for statistical analysis, by using GraphPad Prism software, version 8.1.0. All the experiments were performed independently in triplicate $(n=3)$, and data were presented as mean \pm standard deviation (SD). Values of $p(* * * * p<0.0001$, $\left.{ }^{* * * *} p=0.0003,{ }^{* *} p=0.0045, * p=0.0234\right)$ were considered as statistically significant.

\section{Results}

ETCs inhibit Candida albicans adhesion

Adhesion assay using the vital dye alamarBlue as the detection reagent was used to evaluate the effect of ETC-5, 
Table $\mathbf{2}$ List of primers used for RT-qPCR experiments

\begin{tabular}{|c|c|c|c|c|}
\hline Gene & Primer & Sequence $\left(5^{\prime}-3^{\prime}\right)$ & Amplicon length (bp) & Source \\
\hline ALS1 & Forward Reverse & GCT CCA TCA CCT GCT GTT TC CTG AGG TGC CTG TTG TCA AG & 193 & This study \\
\hline ALS2 & Forward Reverse & TाT AAG GCT GGC ACC AAC AC ATT GTG AAC CCC ATT GCA CC & 203 & This study \\
\hline ALS3 & Forward Reverse & CTA CCG CTG TGA CCA CCT TA CAG TाT CCC CAA TTG GTG CA & 153 & This study \\
\hline ALS9 & Forward Reverse & CGA TाT CAG TTA GCA CCG CA CGT TGA AGT TGG CAC CTC TC & 242 & This study \\
\hline $\mathrm{CPH} 1$ & Forward Reverse & GTC GCC ACC CCA ACC TAT AT AGG AAA CCC AGA AGC GTC AT & 240 & This study \\
\hline HWP1 & Forward Reverse & CTG AAC CTT CCC CAG TTG CT CGA CAG CAC TAG ATT CCG GA & 174 & This study \\
\hline SAP1 & Forward Reverse & $\pi \Pi$ GGT GGG GTT GAC AAA GC ATG ACC TTG ACC GTC CAG $\Pi$ & 234 & This study \\
\hline SAP2 & Forward Reverse & CCG TTG GAT TTG GTG GTG TT AGC ATT ATC AAC CCC ACC GA & 239 & This study \\
\hline SAP3 & Forward Reverse & TGG TCC CCA AGG TGA AAT CA TGT CCT TGA CCA GCT TGA CA & 201 & This study \\
\hline PLB1 & Forward Reverse & ATA TGC TCC TGG TCC GGT TT ATT GCT CTA TAC CCT CCG CC & 231 & This study \\
\hline ACT1 & Forward Reverse & TGG TGA TGA AGC CCA ATC CA CAT TGG AGC TTC GGT CAA CA & 169 & This study \\
\hline PMA1 & Forward Reverse & GAA GGT GCT ACT GAT GCT GC GCA ACA TCA GCG AAA ATG GC & 242 & This study \\
\hline$R P P 2 B$ & Forward Reverse & ACA CCT CTC CAT CAG CTI CT TGG GAC AGA AGC TAA TIT GGT G & 155 & This study \\
\hline
\end{tabular}

ETC-6 and ETC-7 on C. albicans adherence. C. albicans cells after being exposed to different concentrations of test compounds exhibited varying degrees of inhibition of adherence, which indicates that the effect was concentration dependent (Fig. 1). For the control strain C. albicans SC5314 the test compounds were able to inhibit adhesion ranging from 55 to $71 \%, 35-50 \%$ and $25-39 \%$ at $1 \times$ MIC, $0.5 \times$ MIC and $0.25 \times$ MIC respectively. The figures for fluconazole susceptible $C$. albicans 4175 and fluconazole resistant C. albicans 5112 strains were 49$66 \%, 31-46 \%$ and $23-35 \%$ and $39-57 \%, 25-37 \%$ and $16-26 \%$, respectively. The results indicated that these test compounds were significantly effective in reducing C. albicans adhesion, even at sub-inhibitory concentrations.

\section{ETCs inhibit Candida albicans morphogenesis}

The effect of test compounds on yeast to hyphae transition in C. albicans cells were visualized microscopically. After exposure to different concentrations of test entities for $180 \mathrm{~min}$, C. albicans cells showed significant dose dependent inhibition of hyphal growth when compared to their respective control cells, in which more than $90 \%$ of hyphal growth was observed after $180 \mathrm{~min}$ (Fig. 2). When compared to untreated control cells, complete inhibition of hyphal growth was observed in control $C$. albicans SC5314 and fluconazole susceptible C. albicans 4175 strains at $1 \times \mathrm{MIC}$, followed by more than $90 \%$ inhibition at $0.5 \times$ MIC values of test compounds. However, modest hyphal growth and shortened hyphae were observed in these $C$. albicans strains at $0.25 \times$ MIC values of test compounds. Furthermore, against fluconazole resistant strain C. albicans 5112, hyphal growth was absent at $1 \times \mathrm{MIC}$ and modest at $0.5 \times$ MIC. In contrast to fluconazole susceptible isolates, C. albicans 5112 showed hyphal growth at $0.25 \times \mathrm{MIC}$, however not to the same degree as in control cells. All these findings demonstrated the potential of test compounds to inhibit transition of yeast cells to hyphae in both fluconazole susceptible and resistant $C$. albicans cells.

\section{ETCs inhibits Candida albicans hydrolytic enzyme secretion}

We further studied the effect of eugenol tosylate congeners on secretion of hydrolytic enzymes (proteinases and phospholipases) in C. albicans cells. Results showed that C. albicans cells after being exposed to varying concentrations of test compounds inhibited enzyme secretion in a concentration dependent manner when compared to their respective untreated control cells.

Figure 3 summarizes the proteinase activity of tested C. albicans strains. At $1 \times$ MIC, test compounds exhibited $43-57 \%, 37-48 \%$ and $25-37 \%$ proteinase inhibition in control C. albicans SC5314, fluconazole susceptible C. albicans 4175 and fluconazole resistant C. albicans 5112 strains, respectively. At $0.5 \times \mathrm{MIC}$ and $0.25 \times \mathrm{MIC}$ values of test compounds proteinase inhibition in these C. albicans strains was observed in the range of $34-49 \%, 30$ $41 \%, 15-23 \%$ and $15-21 \%, 15-20 \%, 2-15 \%$, respectively. Results demonstrated that test compounds significantly inhibited proteinase secretion in Candida cells. However, in fluconazole resistant C. albicans 5112 strain compounds, ETC-6 and ETC-7 did not have any significant effect on proteinase secretion at $0.25 \times$ MIC value.

Phospholipase enzyme activity results for all tested $C$. albicans strains are summarized in Fig. 4. Test compounds at $1 \times$ MIC and $0.5 \times$ MIC values showed significant inhibition in phospholipase secretion in the range of 35 to $46 \%, 23$ to $33 \%, 24$ to $34 \%$ and 29 to $35 \%, 19$ to $25 \%, 16$ to $22 \%$ in control C. albicans SC5314, 

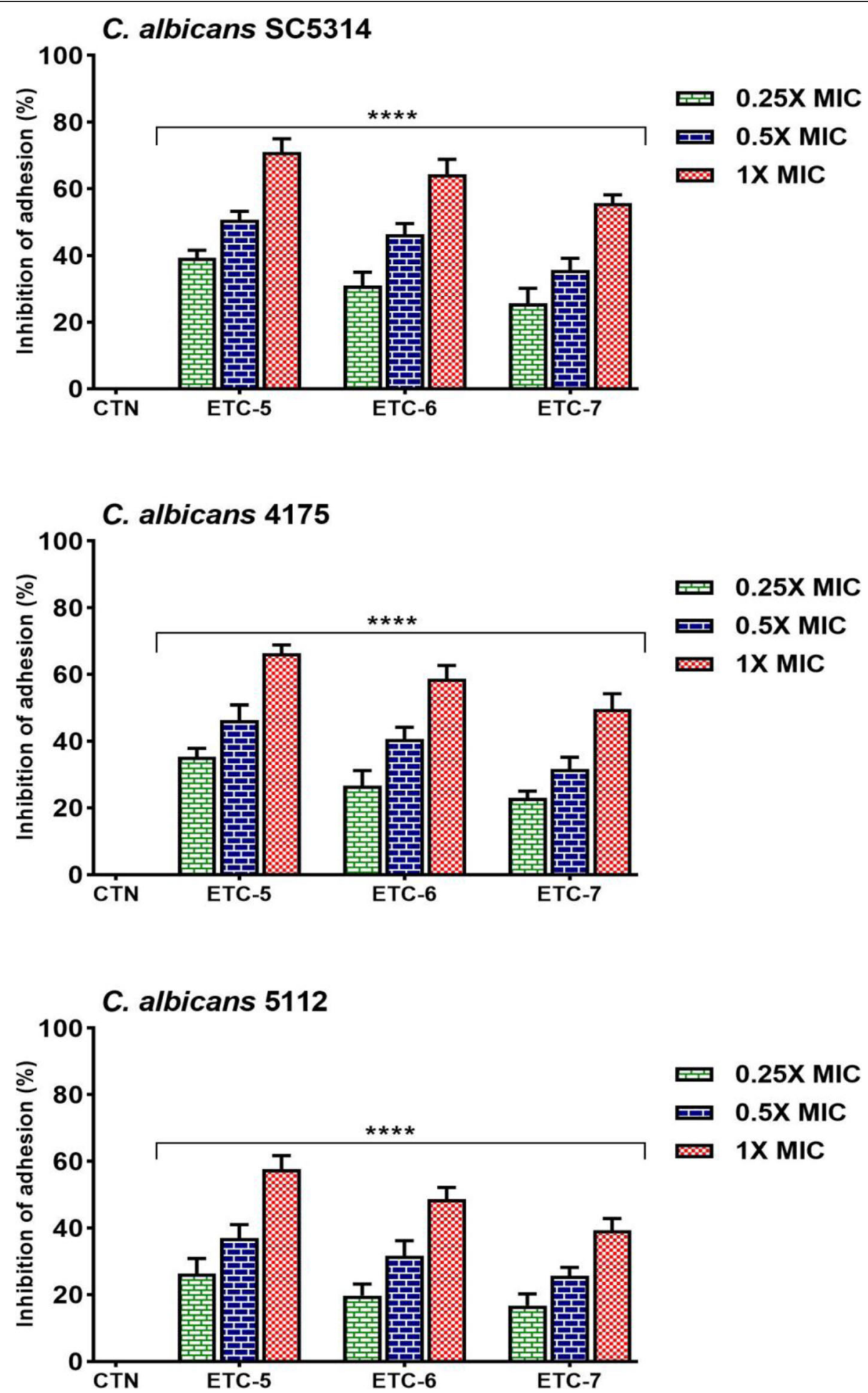

Fig. 1 AlamarBlue-based polystyrene adhesion assay was used to evaluate the effect of test compounds on C. albicans adherence. Control $C$. albicans SC5314, fluconazole susceptible C. albicans 4175 and fluconazole resistant C. albicans 5112 strains were exposed to $0.25 \times$ MIC, $0.5 \times$ MIC and $1 \times \mathrm{MIC}$ values of test compounds for $3 \mathrm{~h}$ at $37^{\circ} \mathrm{C}$. Control bars (CTN) indicate untreated cells, accepted as $0 \%$ inhibition. Data are presented from three independent experiments using means \pm S.D. ${ }^{* * *} p<0.0001$ 

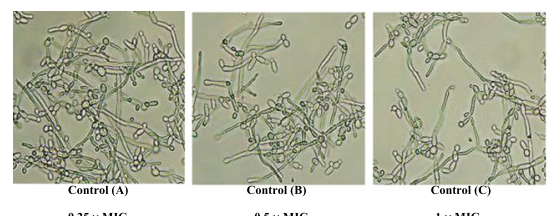

$0.5 \times \mathrm{MIC}$ $1 \times$ MIC
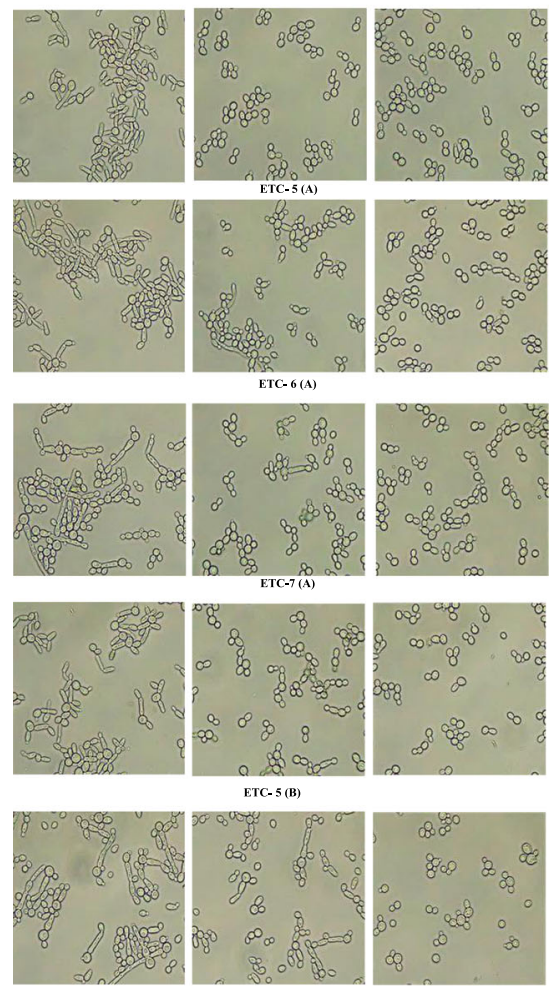

ETC- 6 (B)
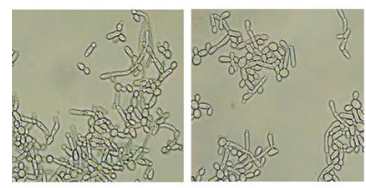

ETC-7(B)
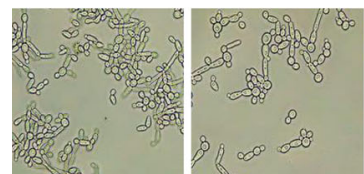

ETC 5 (C)

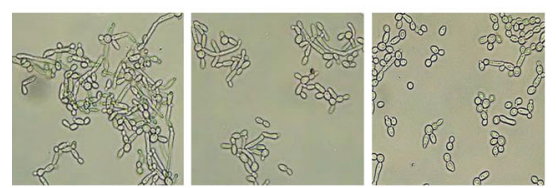

ETC- 6 (C)
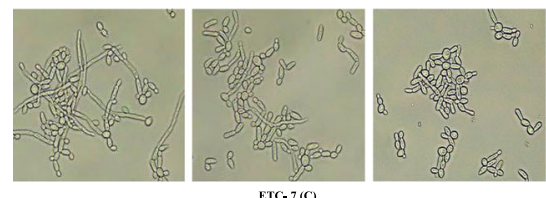

Fig. 2 Yeast to hyphae transition in Candida albicans cells. Candida cells were grown in SD broth containing $10 \%$ FBS with $0.25 \times \mathrm{MIC}$, $0.5 \times \mathrm{MIC}$ and $1 \times \mathrm{MIC}$ values of test compounds at $37^{\circ} \mathrm{C}$ for 180 min. After incubation, an aliquot was taken from each sample and observed microscopically at 60X magnification. An untreated sample was used as control. The letters A, B and C represent control strain C. albicans SC5314, fluconazole susceptible strain C. albicans 4175 and fluconazole resistant strain C. albicans 5112 respectively

fluconazole susceptible $C$. albicans 4175 and fluconazole resistant C. albicans 5112 strains, respectively. At $0.25 \times$ MIC values, test compounds demonstrated significant inhibition in the phospholipase enzyme activity varying from 12 to $17 \%$ in standard strain, 15 to $21 \%$ in fluconazole susceptible strain and 8 to $16 \%$ fluconazole resistant strain of C. albicans. In fluconazole resistant $C$. albicans 5112 strain compound ETC-7 at $0.25 \times$ MIC value did not significantly inhibit phospholipase enzyme secretion. These results indicated that test compounds decreased hydrolytic enzyme secretion in C. albicans cells to a varying extent.

\section{ETCs inhibits Candida albicans biofilm formation}

Semi-quantitative XTT reduction assay was performed to observe the effect of test compounds on C. albicans biofilm formation. Significant inhibition in biofilm formation was observed in C. albicans cells after treatment with different concentrations of test compounds for 24 and $48 \mathrm{~h}$ (Fig. 5). At concentrations of $1 \times$ MIC, $0.5 \times$ MIC and $0.25 \times$ MIC of test entities inhibition in biofilm formation in control strain C. albicans SC5314 was observed in the range of 52 to $77 \%, 30$ to $59 \%$ and 17 to $44 \%$, respectively. These ranges of percentage inhibition in biofilm formation in fluconazole susceptible C. albicans 4175 were found between 44 to $77 \%, 24$ to $51 \%$ and 10 to $40 \%$, respectively. Interestingly, significant inhibition in biofilm formation was also observed in fluconazole resistant $C$. albicans 5112 strain and the ranges were between 34 to $58 \%, 14$ to $43 \%$ and 7 to $31 \%$ at $1 \times$ MIC, $0.5 \times$ MIC and $0.25 \times$ MIC of test entities, respectively. Moreover, the rate of inhibition in biofilm formation by these test compounds was depended on concentration and treatment time. Our results showed that these ETCs drastically reduced biofilm formation in C. albicans cells.

\section{ETCs downregulates Candida albicans pathogenicity associated genes}

Effect of test compounds (ETC-5, ETC-6 and ETC-7) on expression of important pathogenicity related genes (ALS1, ALS2, ALS3, ALS9, CPH1, HWP1, SAP1, SAP2, $S A P 3$ and PLB1) in C. albicans cells was tested and the results are summarized in Fig. 6 . The expressions of the indicated genes are shown as relative values in 


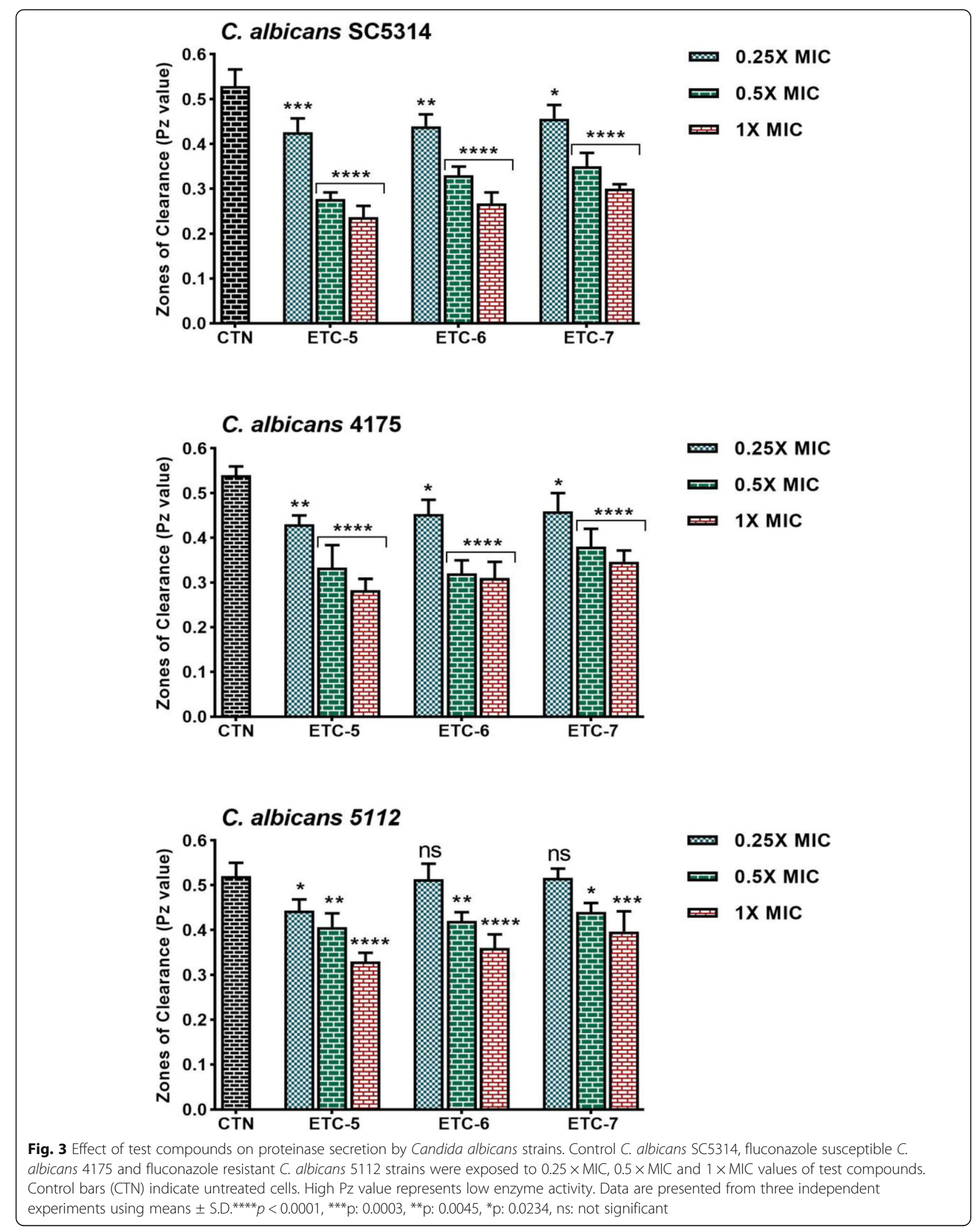




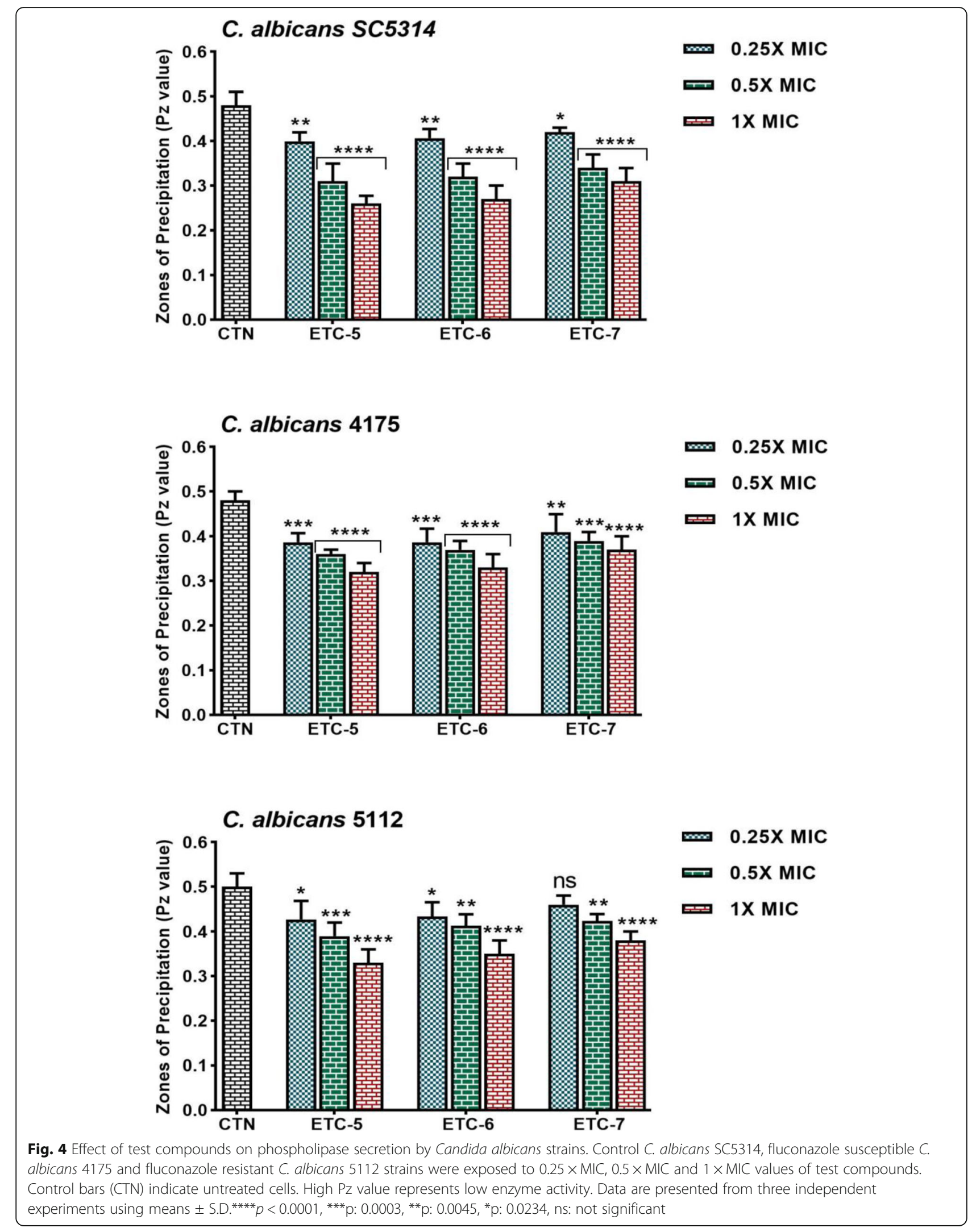



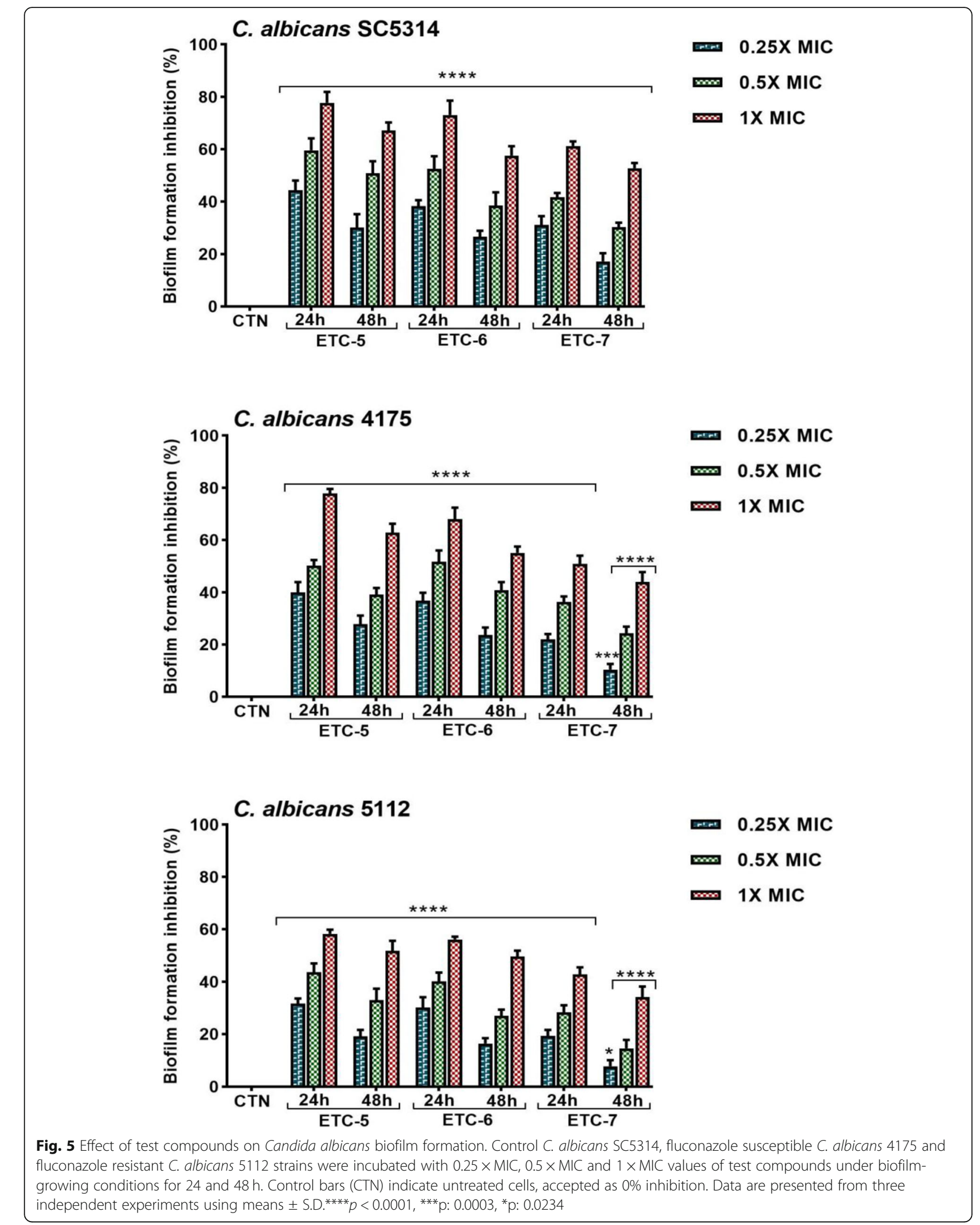

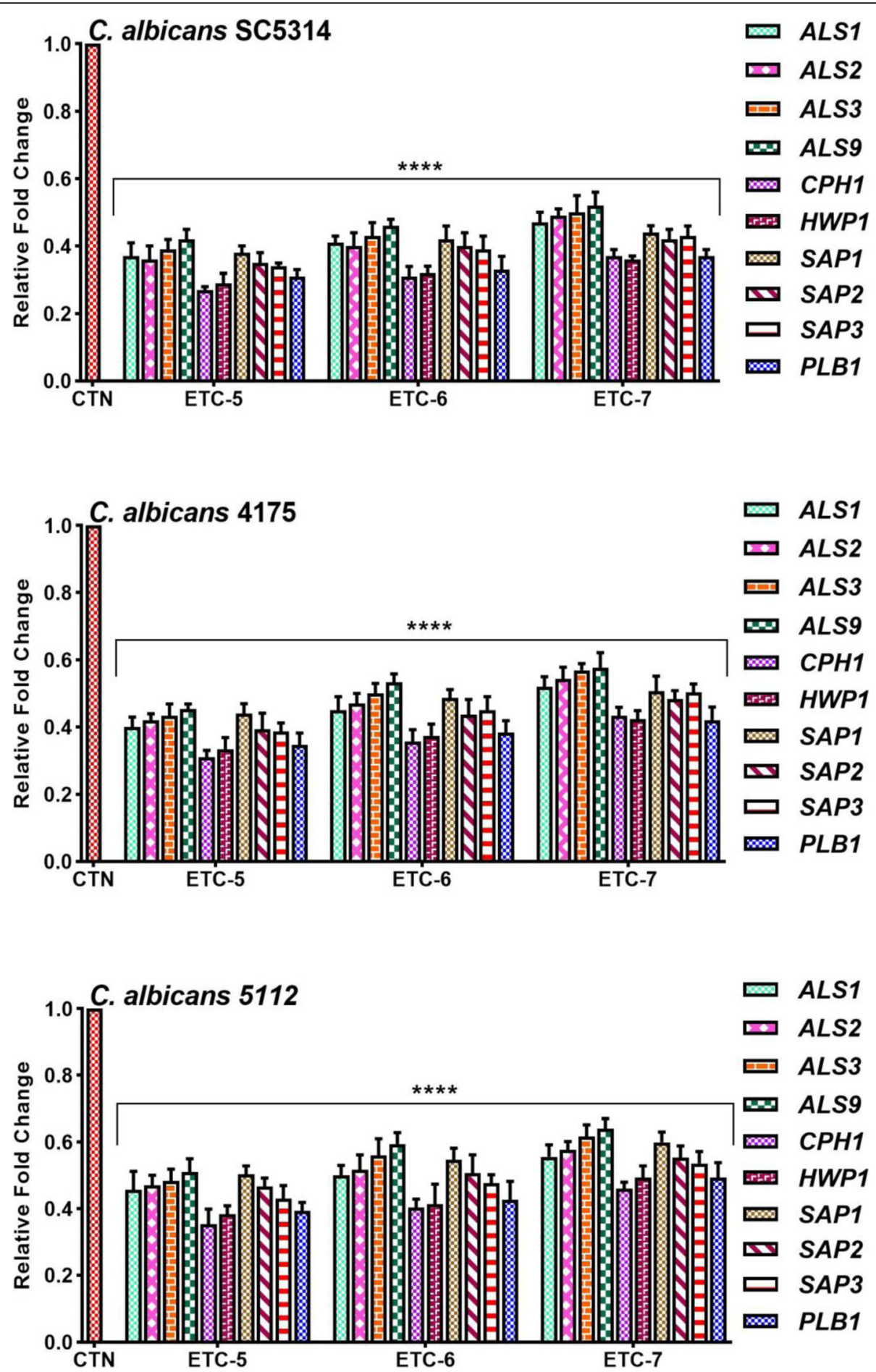

Fig. 6 Relative expression of indicated genes after normalization to housekeeping genes (ACT1, PMA1 and RPP2B) in control C. albicans SC5314, fluconazole susceptible C. albicans 4175 and fluconazole resistant C. albicans 5112 strains after exposure to test compounds (ETC-5, ETC-6 and ETC-7) at their respective MIC values. Cells without drug treatment (CTN) were used as negative control. Data are presented from three independent experiments using means of fold changes \pm S.D.**** $p<0.0001$

comparison to the control (untreated cells) that were set to 1.0. Expression levels of all the indicated genes was down regulated significantly as compared to control cells when treated at MIC values of these test compounds. Expression of genes related to adherence (ALS1, ALS2, $A L S 3$ and ALS9), morphogenesis (CPH1, HWP1), 
proteinases (SAP1, SAP2, and SAP3) and phospholipases (PLB1) in ETCs treated C. albicans SC5314 was reduced significantly with a fold range of 1.9 to $2.8,2.7$ to $3.7,2.3$ to 2.9 and 2.7 to 3.2 folds, respectively. These figures for fluconazole susceptible $C$. albicans 4175 and fluconazole resistant C. albicans 5112 were in the range of 1.8 to $2.5,2.3$ to $3.2,2.0$ to $2.6,2.4$ to 2.9 and 1.6 to $2.2,2.0$ to 2.9, 1.7 to $2.3,2.0$ to 2.6 folds, respectively. From these results it can be concluded that ETCs downregulated the expression of the above-mentioned genes, not only in fluconazole susceptible $C$. albicans but also in fluconazole resistant $C$. albicans cells.

\section{Discussion}

Invasive fungal infections caused by different Candida species have increased considerably over the past few decades and has become a menace to global health. The unavailability of sufficient antifungal drugs and potential toxicity of currently available antifungals has restricted antifungal therapy. The development of new antifungal agents is restricted due to the limited number of known drug targets in fungi $[20,30]$. These factors in turn amplify the emergence of resistance to the available antifungal agents and accentuate the need for development of novel antifungal drugs with different target sites. Based on these facts, we targeted major virulence factors in $C$. albicans such as adherence, morphological transition, secretion of aspartyl proteinase and phospholipases and biofilm formation by semi-synthetic ETCs. Several other studies have also reported antifungal activity of eugenol (parent compound for these tosylate congeners) and its derivatives [21-23]. Therefore, targeting virulence factors could be a new paradigm for the development of new and effective antifungal drugs with multiple drug targets.

C. albicans cells carry specialized proteins known as adhesins, which facilitate adherence to host cells and abiotic surfaces [31, 32]. In C. albicans agglutinin-like sequence (ALS) proteins (Als1 to Als7 and Als9) are well studied adhesins that encode cell surface glycoproteins. From the ALS family Als3 (hyphae associated) is particularly crucial for adhesion [33, 34]. From the results it was observed that the test compounds ETC-5, ETC-6 and ETC-7 significantly inhibited adherence in C. albicans in a dose-dependent manner with a range of 16$71 \%$, and down regulated expression of adherence related genes (ALS1, ALS2, ALS3 and ALS9) up to 1.92.8 folds. Furthermore, $C$. albicans adherence to host tissues and implanted medical devices leads to the formation of biofilms. Biofilm is one of the important virulence factor in C. albicans, which increases resistance to most conventional antifungal drugs [35]. Moreover, several studies have been reported that $C$. albicans biofilms are more resistant (up to a 1000 times) than planktonic cells to current antifungal therapy and it is assumed this resistance is due to the presence of matrix, which limits the penetration of these agents by creating a diffusion barrier [36-39]. Here, we found that ETCs drastically inhibited biofilm formation in a concentration dependent manner between 7 and $77 \%$ in both fluconazole susceptible and resistant $C$. albicans strains. We presume that ETCs target the membrane adhesin proteins which facilitate adherence thereby preventing adherence to host cells and abiotic surfaces, while subsequently inhibiting biofilm formation.

C. albicans has the capability of dimorphic switching (yeast to hyphae transition), one of its main virulence factor [13]. Hyphal forms of C. albicans not only play an essential role in biofilm formation [40], but are also important in facilitating C. albicans invasion into the host tissues thereby resulting in pathogenesis. Studies also reported that $C$. albicans in the hyphal form are more invasive than the yeast form [41]. Furthermore, various genes directly or indirectly are associated with hyphal formation which includes HWP1, ALS1, ALS3 and CPH1 $[8,42]$. From the microscopic images it was revealed that ETCs at their MIC values completely inhibited hyphal growth and at $0.5 \times \mathrm{MIC}$ values more than $90 \%$ hyphae formation was inhibited. These results indicate that test compounds had a potent inhibitory effect on morphological transitions in C. albicans resulting in lack of hyphal growth. To understand the mechanism of ETCs in hyphal growth inhibition at molecular level, expression profile of genes related to hyphal growth were analyzed. Expression of HWP1, CPH1, ALS1 and ALS3 was reduced by $2.0-3.4$ folds, $2.1-3.7$ folds, $1.8-2.7$ folds and 1.6-2.6 folds, respectively. These results demonstrated that the test compounds can potentially inhibit hyphae formation significantly by down regulating the expression of different hyphal genes. Previous studies have already reported a reduction in expression of the hyphae related genes resulting in inhibition of hyphal formation in C. albicans [8].

C. albicans is also capable of secreting extracellular hydrolytic enzymes, one of the important virulence traits that contribute in its pathogenicity. Secreted aspartyl proteinases (SAPs) and phospholipases (PLBs) are main enzymes which play an important role in adherence, invasion and damage of the host tissues [43]. Genes involved in secretion of hydrolytic enzymes mainly SAPs and PLBs are responsible for adherence, tissue damage, alteration in the host immune response and tissue invasion, disruption of host cell membrane, respectively $[44,45]$. From the results, significant reduction in enzyme secretion was observed in cells after exposure to different concentrations of test compounds. This reduction amounted to between 2 and $57 \%$ and $8-46 \%$ for proteinases and phospholipases, respectively. Moreover, 
ETCs significantly down regulated expression of SAP1, SAP2, SAP3 and PLB1 genes by a fold range of 1.7-2.9 folds and 2.0-3.2 folds, respectively. The combined results from all the above assays exhibited a significant effect of ETCs on the major virulence factors in both fluconazole susceptible and resistant C. albicans strains.

This is a first study reporting the effect of eugenol derivatives on virulence factors of $C$. albicans; however, several studies have reported the effect of eugenol on virulence factors. A study by Raut and colleagues, showed eugenol significantly prevents morphogenesis, adhesion and biofilm development in $C$. albicans at MIC values of $0.031 \mathrm{mg} / \mathrm{ml}, 2 \mathrm{mg} / \mathrm{ml}$ and $0.5 \mathrm{mg} / \mathrm{ml}$ respectively [28]. In an another study, preformed biofilm of $C$. albicans treated with eugenol at $500 \mathrm{mg} / \mathrm{L}$ and $2000 \mathrm{mg} / \mathrm{L}$ for $48 \mathrm{~h}$ showed 50 and > $80 \%$ reduction in the metabolic activity of biofilms respectively [46]. Halbandge et al., 2017 reported that eugenol at MIC value of $0.062 \mathrm{mg} / \mathrm{ml}$ inhibited invasive growth of $C$. albicans [47]. Our results are in agreement with these previous findings where eugenol was reported to have antifungal activity by targeting major virulence factors in C. albicans. However, when compared to these previous findings our results showed improved activity of these derivatives on virulence factors of C. albicans and proved that modifications in eugenol to synthesize eugenol derivatives not only enhanced the antifungal activity but also drastically decreased the MIC values of the compound. Results also revealed ETC- 5 as the most active compound followed by ETC-6 and ETC-7, respectively.

\section{Conclusion}

In conclusion, ETCs having potent antifungal activity also target major virulence factors of $C$. albicans and thereby inhibit the pathogenicity of this commensal microbe at the initial stages. These compounds significantly diminished C. albicans pathogenicity in terms of adherence, morphological transition, secretion of hydrolytic enzymes and biofilm formation both at biochemical as well as at molecular level. The in vitro results advocate further studies using animal models to reveal the indepth mechanisms of these ETCs behind their antifungal activity, which may take these compounds to the next stage of drug development.

\section{Abbreviations}

ETCs: Eugenol tosylate congeners; RT-qPCR: Quantitative reverse transcription PCR; ATCC: American type culture collection; SDB: Sabouraud Dextrose broth; SDA: Sabouraud Dextrose Agar; MIC: Minimum inhibitory concentration;

FBS: Fetal bovine serum; BSA: Bovine Serum Albumin; NaCl: Sodium chloride; $\mathrm{CaCl}_{2}$ : Calcium chloride; PBS: Phosphate-Buffered Saline; MOPS: (3-(Nmorpholino) propanesulfonic acid); API: Analytical profile index; ALS: Agglutinin-like sequence; SAPs: Secreted aspartyl proteinases; PLBs: Phospholipases

\section{Authors' contributions}

Conceived and designed the experiments: AA. Performed the experiments: SAL. Analyzed the data: SAL AA. Contributed reagents/materials/analysis tools: AA. Wrote the paper: SAL. The author(s) read and approved the final manuscript.

\section{Funding}

We gratefully acknowledge financial support from University Research Committee Grant for 2019 - Friedel Sellschop Award (Grant No: AZMD019) Wits Faculty of Health Sciences Research Committee (FRC, Grant no: 001... 5254).

\section{Availability of data and materials Not applicable.}

\section{Ethics approval and consent to participate}

This study was approved by the Human Research Ethics Committee of University of the Witwatersrand (Johannesburg, South Africa). Existing stock cultures of Candida albicans used in this study were stored in the department of Clinical Microbiology and Infectious Diseases, University of the Witwatersrand, Johannesburg, South Africa.

\section{Consent for publication}

Not applicable.

\section{Competing interests}

We have no competing interests to declare.

Received: 27 November 2019 Accepted: 16 April 2020

Published online: 29 April 2020

\section{References}

1. Pfaller M, Neofytos D, Diekema D, Azie N, Meier-Kriesche HU, Quan SP, Horn D. Epidemiology and outcomes of candidemia in 3648 patients: data from the prospective antifungal therapy (PATH Alliance(R)) registry, 2004-2008. Diagn Microbiol Infect Dis. 2012;74:323-31.

2. Wenzel RP, Gennings C. Bloodstream infections due to Candida species in the intensive care unit: identifying especially highrisk patients to determine prevention strategies. Clin Infect Dis. 2005;41:S389-93.

3. Bongomin F, Gago S, Oladele RO, Denning DW. Global and Multi-National Prevalence of Fungal Diseases-Estimate Precision. J Fungi (Basel). 2017;3:57.

4. Brown GD, Denning DW, Gow NA, Levitz SM, Netea MG, White TC. Hidden killers: human fungal infections. Sci Transl Med. 2012;4:165rv13.

5. Sievert DM, Ricks P, Edwards JR, Schneider A, Patel J, Srinivasan A, Kallen A, Limbago B, Fridkin S, National Healthcare Safety Network (NHSN) Team, and Participating NHSN Facilities. Antimicrobial-resistant pathogens associated with healthcare-associated infections: summary of data reported to the National Healthcare Safety Network at the Centers for Disease Control and Prevention, 2009-2010. Infect Control Hosp Epidemiol. 2013;34:1-14.

6. Friedman DZP, Schwartz IS. Emerging fungal infections: New Patients, new Patterns, and new pathogens. J Fungi (Basel). 2019;5(3):67.

7. Lindberg E, Hammarström H, Ataollahy N, Kondori N. Species distribution and antifungal drug susceptibilities of yeasts isolated from the blood samples of patients with candidemia. Sci Rep. 2019;9:3838.

8. Haque F, Alfatah M, Ganesan K, Bhattacharyya MS. Inhibitory effect of Sophorolipid on Candida albicans biofilm formation and Hyphal growth. Sci Rep. 2016;6:23575.

9. Pappas PG, Kauffman CA, Andes DR, Clancy CJ, Marr KA, Ostrosky-Zeichner L, Reboli AC, Schuster MG, Vazquez JA, Walsh TJ, et al. Executive summary: clinical practice guideline for the Management of Candidiasis: 2016 update by the Infectious Diseases Society of America. Clin Infect Dis. 2016;62:40917.

10. Mayer FL, Wilson D, Hube B. Candida albicans pathogenicity mechanisms. Virulence. 2013;4:119-28.

11. Sudbery P, Gow N, Berman J. The distinct morphogenic states of Candida albicans. Trends Microbiol. 2004;12:317-24.

12. Saville SP, Lazzell AL, Monteagudo C, Lopez-Ribot JL. Engineered control of cell morphology in vivo reveals distinct roles for yeast and filamentous forms of Candida albicans during infection. Eukaryot Cell. 2003;2:1053-60.

13. Lo HJ, Köhler JR, DiDomenico B, Loebenberg D, Cacciapuoti A, Fink GR. Non filamentous C. albicans mutants are avirulent. Cell. 1997;90:939-49. 
14. Finkel JS, Mitchell AP. Genetic control of Candida albicans biofilm development. Nat Rev Microbiol. 2011;9:109-18.

15. Khan A, Ahmad A, Xess I, Khan LA, Manzoor N. Ocimum sanctum essential oil inhibits virulence attributes in Candida albicans. Phytomedicine. 2014;21: 448-52.

16. Ramage G, Wickers BL, Lopez-Ribot JL. Biofilms of Candida albicans and their associated resistance to antifungal agents. Am Clin Lab. 2001;20:42-4.

17. Laniado-Laborin R, Cabrales-Vargas MN. Amphotericin B: side effects and toxicity. Rev Iberoam Micol. 2009;26:223-7.

18. Sharma S, Alfatah M, Bari VK, Rawal Y, Paul S, Ganesan K. Sphingolipid biosynthetic pathway genes FEN1 and SUR4 modulate amphotericin B resistance. Antimicrob Agents Chemother. 2014;58:2409-14.

19. Ahmad A, Wani MY, Khan A, Manzoor N, Molepo J. Synergistic interactions of Eugenol-tosylate and its congeners with fluconazole against Candida albicans. PLoS One. 2015;10:e0145053.

20. Ahmad A, Molepo J, Patel M. Challenges in the development of antifungal agents against Candida: scope of phytochemical research. Curr Pharm Des. 2016;22:4135-50.

21. Carrasco H, Raimondi M, Svetaz L, Di Liberto M, Rodriguez MV, Espinoza L, Madrid A, Zacchino S. Antifungal activity of eugenol analogues. Influence of different substituents and studies on mechanism of action. Molecules. 2012; 17:1002-24.

22. Hipólito TMM, Bastos GTL, Barbosa TWL, de Souza TB, Coelho LFL, Dias ALT, Rodríguez IC, Dos Santos MH, Dias DF, Franco LL, et al. Synthesis, activity, and docking studies of eugenol-based glucosides as new agents against Candida sp. Chem Biol Drug Des. 2018;92:1514-24.

23. da Silva FFM, Monte FJQ, de Lemos TLG. Do Nascimento PGG, de Medeiros Costa AK, de Paiva LMM. Eugenol derivatives: synthesis, characterization, and evaluation of antibacterial and antioxidant activities. Chem Cent J. 2018; 12:34.

24. Lone SA, Wani MY, Fru P, Ahmad A. Cellular apoptosis and necrosis as therapeutic targets for novel Eugenol Tosylate congeners against Candida albicans. Sci Rep. 2020;10:1191.

25. Fazly A, Jain C, Dehner AC, Issi L, Lilly EA, Ali A, Cao H, Fidel PL Jr, Rao RP, Kaufman PD. Chemical screening identifies filastatin, a small molecule inhibitor of Candida albicans adhesion, morphogenesis, and pathogenesis. Proc Natl Acad Sci U S A. 2013;110:13594-9.

26. Yousuf S, Ahmad A, Khan A, Manzoor N, Khan LA. Effect of garlic-derived allyl sulphides on morphogenesis and hydrolytic enzyme secretion in Candida albicans. Med Mycol. 2011;49:444-8.

27. Price MF, Wilkinson ID, Gentry LO. Plate method for detection of phospholipase activity in Candida albicans. Sabouraudia. 1982;20:7-14.

28. Raut JS, Shinde RB, Chauhan NM, Karuppayil SM. Terpenoids of plant origin inhibit morphogenesis, adhesion, and biofilm formation by Candida albicans. Biofouling. 2013;29:87-96.

29. Jin Y, Samaranayake LP, Samaranayake Y, Yip HK. Biofilm formation of Candida albicans is variably affected by saliva and dietary sugars. Arch Oral Biol. 2004;49:789-98.

30. Gauwerky K, Borelli C, Korting HC. Targeting virulence: a new paradigm for antifungals. Drug Discov Today. 2009;14:214-22.

31. Garcia MC, Lee JT, Ramsook CB, Alsteens D, Dufrêne YF, Lipke PN. A role for amyloid in cell aggregation and biofilm formation. PLoS One. 2011;6: e17632.

32. Verstrepen $\mathrm{KJ}$, Klis FM. Flocculation, adhesion and biofilm formation in yeasts. Mol Microbiol. 2006;60:5-15.

33. Phan QT, Myers CL, Fu Y, Sheppard DC, Yeaman MR, Welch WH, Ibrahim AS, Edwards JE Jr, Filler SG. Als3 is a Candida albicans invasion that binds to cadherins and induces endocytosis by host cells. PLoS Biol. 2007;5:e64

34. Murciano C, Moyes DL, Runglall M, Tobouti P, Islam A, Hoyer LL, Naglik JR. Evaluation of the role of Candida albicans agglutinin-like sequence (Als) proteins in human oral epithelial cell interactions. PLoS One. 2012;7:e33362.

35. Nett JE. Future directions for anti-biofilm therapeutics targeting Candida. Expert Rev Anti-Infect Ther. 2014;12:375-82.

36. Tobudic S, Lassnigg A, Kratzer C, Graninger W, Presterl E. Antifungal activity of amphotericin B, caspofungin and posaconazole on Candida albicans biofilms in intermediate and mature development phases. Mycoses. 2010; 53:208-14.

37. Tobudic S, Kratzer C, Lassnigg A, Presterl E. Antifungal susceptibility of Candida albicans in biofilms. Mycoses. 2012;55:199-204.

38. Sardi JC, Scorzoni L, Bernardi T, Fusco-Almeida AM, Mendes Giannini MJ. Candida species: current epidemiology, pathogenicity, biofilm formation, natural antifungal products and new therapeutic options. J Med Microbiol. 2013;62:10-24.

39. Nett JE, Sanchez H, Cain MT, Ross KM, Andes DR. Interface of Candida albicans biofilm matrix-associated drug resistance and cell wall integrity regulation. Eukaryot Cell. 2011;10:1660-9.

40. Sudbery PE. Growth of Candida albicans hyphae. Nat Rev Microbiol. 2011;9: 737-48.

41. Berman J, Sudbery PE. Candida Albicans: a molecular revolution built on lessons from budding yeast. Nat Rev Genet. 2002;3:918-30.

42. Staniszewska M, Bondaryk M, Zukowski K, Chudy M. Role of SAP7-10 and morphological regulators (EFG1, CPH1) in Candida albicans hypha formation and adhesion to colorectal carcinoma caco-2. Pol J Microbiol. 2015;64:20310.

43. Silva S, Negri M, Henriques M, Oliveira R, Williams DW, Azeredo J. Candida glabrata, Candida parapsilosis and Candida tropicalis: biology, epidemiology, pathogenicity and antifungal resistance. FEMS Microbiol Rev. 2012;36:288305.

44. Naglik JR, Rodgers CA, Shirlaw PJ, Dobbie JL, Fernandes-Naglik LL, Greenspan D, Agabian N, Challacombe SJ. Differential expression of Candida albicans secreted aspartyl proteinase and phospholipase B genes in humans correlates with active oral and vaginal infections. J Infect Dis. 2003;188:46979.

45. Mavor AL, Thewes S, Hube B. Systemic fungal infections caused by Candida species: epidemiology, infection process and virulence attributes. Curr Drug Targets. 2005;6:863-74

46. He M, Du M, Fan M, Bian Z. In vitro activity of eugenol against Candida albicans biofilms. Mycopathologia. 2007;163:137-43.

47. Halbandge SD, Mortale SP, Jadhav AK, Kharat K, Karuppayil SM. Differential sensitivities of various growth modes of Candida albicans to sixteen molecules of plant origin. J Pharmacogn Phytochem. 2017;6:306-18.

\section{Publisher's Note}

Springer Nature remains neutral with regard to jurisdictional claims in published maps and institutional affiliations.

Ready to submit your research? Choose BMC and benefit from

- fast, convenient online submission

- thorough peer review by experienced researchers in your field

- rapid publication on acceptance

- support for research data, including large and complex data types

- gold Open Access which fosters wider collaboration and increased citations

- maximum visibility for your research: over $100 \mathrm{M}$ website views per year

At BMC, research is always in progress.

Learn more biomedcentral.com/submissions 